\title{
Devil's Foot/Jambul
}

National Cancer Institute

\section{Source}

National Cancer Institute. Devil's Foot/Jambul. NCI Thesaurus. Code C28980.

An herbal combination of two plants, devil's claw (Harpagophytum procumbens) and jambul (Eugenia jambolana) that may be administered both orally and topically in various formulations. Devil's claw has been used as a tonic, as a hypoglycemic, to cleanse the lymph system, and in the treatment of arthritis and rheumatism. This agent may have anti-inflammatory and analgesic properties, possibly due to the presence of antioxidants, phenols, tannins, triterpenoids and volatile oils. Jambul seeds and fruits have important carminative and astringent properties and may reduce blood sug ar levels. This agent contains glucosides, jamboline and ellagic acid which may check the conversion of starch into sugar. ( $\mathrm{NCl04)}$ 